San Jose State University

SJSU ScholarWorks

Master's Theses

Master's Theses and Graduate Research

1995

\title{
Solvolysis of sulfonates in ternary mixtures of ethanol, TFE, and $\mathrm{CHCl}_{3}$ or $\mathrm{CCl}_{4}$
}

Dimitra Gousi

San Jose State University

Follow this and additional works at: https://scholarworks.sjsu.edu/etd_theses

\section{Recommended Citation}

Gousi, Dimitra, "Solvolysis of sulfonates in ternary mixtures of ethanol, TFE, and $\mathrm{CHCl}_{3}$ or $\mathrm{CCl}_{4}$ " (1995). Master's Theses. 1069.

DOI: https://doi.org/10.31979/etd.hren-6sws

https://scholarworks.sjsu.edu/etd_theses/1069

This Thesis is brought to you for free and open access by the Master's Theses and Graduate Research at SJSU ScholarWorks. It has been accepted for inclusion in Master's Theses by an authorized administrator of SJSU ScholarWorks. For more information, please contact scholarworks@sjsu.edu. 


\section{INFORMATION TO USERS}

This manuscript has been reproduced from the microfilm master. UMI films the text directly from the original or copy submitted. Thus, some thesis and dissertation copies are in typewriter face, while others may be from any type of computer printer.

The quality of this reproduction is dependent upon the quality of the copy submitted. Broken or indistinct print, colored or poor quality illustrations and photographs, print bleedthrough, substandard margins, and improper alignment can adversely affect reproduction.

In the unlikely, event that the author did not send UMI a complete mamuscript and there are missing pages, these will be noted. Aiso, if unauthorized copyright material had to be removed, a note will indicate the deletion.

Oversize materials (e.g., maps, drawings, charts) are reproduced by sectioning the original, beginning at the upper left-hand corner and contiming from left to right in equal sections with small overlaps. Each original is also photographed in one exposure and is included in reduced form at the back of the book

Photographs included in the original manuscript have been reproduced xerographically in this copy. Higher quality $6^{\prime \prime} \times 9^{\prime \prime}$ black and white photographic prints are available for any photographs or illustrations appearing in this copy for an additional charge. Contact UMI directly to order.

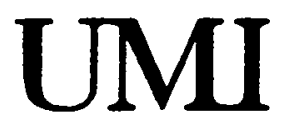

A Bell \& Howell information Company 300 North Zeeb Road. Ann Afbor. MI 48106-1346 USA $313: 761-4700 \quad 800: 521-0600$ 


\section{$-$}




\title{
SOLVOLYSIS OF SULFONATES IN TERNARY MIXTURES OF ETHANOL, TFE, AND $\mathrm{CHCl}_{3} \mathrm{OR} \mathrm{CCl}_{4}$
}

\author{
A Thesis \\ Presented to \\ The Faculty of the Department of Chemistry \\ San Jose State University
}

\author{
In Partial Fulfillment \\ of the Requirements for the Degree \\ Master of Science
}

by

Dimitra Gousi

August, 1995 
UMI Number: 1375693

UMI Microform 1375693

Copyright 1995, by UMI Company. All rights reserved.

This microform edition is protected against unautiorized copying under Title 17, Onited States Code.

\section{UMI}

300 North Zeeb Road

Ann Arbor, MI 48103 
(C) 1995

Dimitra Gousi

ALL RIGHTS RESERVED 
APPROVED FOR THE DEPARTMENT OF CHEMISTRY

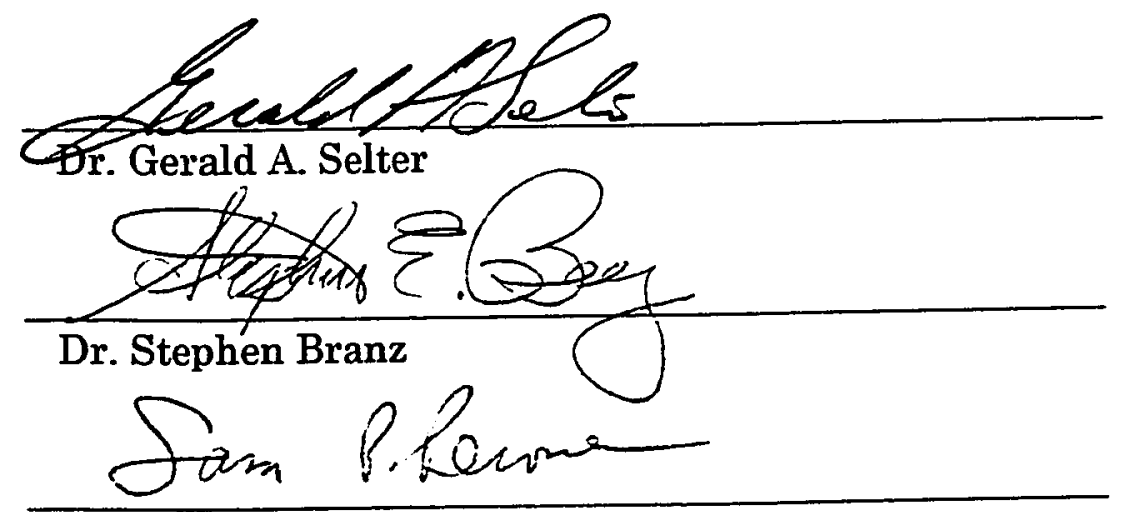

Dr. Sam Perone

APPROVED FOR THE UNIVERSITY

In. Low Lewardonotic 


\begin{abstract}
SOLVOLYSIS OF SULFONATES IN TERNARY MIXTURES OF

ETHANOL, TFE, AND $\mathrm{CHCl}_{3} \mathrm{OR} \mathrm{CCl}_{4}$

by Dimitra Gousi

Solvolysis rate constants and product distributions for 2-AdOTs and [2.2.2]-OTs in ternary solvent mixtures of 2.2.2-trifluoroethanol (TFE), ethanol (EtOH) and either $\mathrm{CHCl}_{3}$ or $\mathrm{CCl}_{4}$, are reported. In all cases the observed rates $\left(k_{0 b s}\right)$ increase as the TFE content of the medium increases. The logarithms of the rate constants (log $\mathrm{k}_{\mathrm{obs}}$ ) correlate linearly with the mole fraction of any of the solvent components for both substrates. Similar behavior is observed for the logarithms of the rate constants for product formation ( $\mathrm{k}_{\mathrm{ROTFE}}$ and $\mathrm{k}_{\mathrm{ROE}}$ ). Product studies in TFE-EtOH, and $\mathrm{CHCl}_{3}$ or $\mathrm{CCl}_{4}$ indicate a preference for the TFE-ether product at all solvent compositions. Selectivities for TFE-ether product over EtOH-ether product increase with increasing $\mathrm{CHCl}_{3}$ and $\mathrm{CCl}_{4}$ mole fraction. Based on the observed data, rate-limiting diffusional separation of an intimate ion pair is proposed as a mechanistic model.
\end{abstract}




\section{ACKNOWLEDGMENTS}

I would like to express my sincere gratitude to Dr. Gerald A. Selter for his guidance and support throughout the difficult course of my thesis. I would like also to thank Dr. Stephen E. Branz and Dr. Sam Perone for challenging me to become a knowledgeable spectator in the chemistry field.

Finally, I would like to acknowledge my husband who has taught me that my life is a task to be done, something I must do myself. 


\section{TABLE OF CONTENTS}

Acknowledgments........................... v

Table of Contents............................. vi

List of Tables..................................... vii

List of Figures................................. viii

Introduction...................................... 1

Experimental Section........................ 10

Treatment of the Data....................... 14

Results.......................................... 15

Discussion....................................... 18

References........................................ 25 


\section{LIST OF TABLES}

Table I: $\quad$ Solvolysis products and rates of 2-AdOTs in TFEEtOH and $\mathrm{CHCl}_{3}$ Media at $90^{\circ} \mathrm{C}$.........................

Table II: $\quad$ Solvolysis products and rates of 2-AdOTs in TFEEtOH and $\mathrm{CCl}_{4} \mathrm{Media}$ at $90{ }^{\circ} \mathrm{C}$.

Table III: Solvolysis products and rates of [2.2.2]-OTs in TFE-EtOH and $\mathrm{CHCl}_{3}$ Media at $90^{\circ} \mathrm{C}$.

Table IV: Solvolysis products and rates of [2.2.2]-OTs in TFE-EtOH and $\mathrm{CCl}_{4} \mathrm{Media}$ at $90^{\circ} \mathrm{C}$.

Table V: $\quad$ Summary of slopes for $\log \mathrm{k}_{\mathrm{obs}}$ versus Mole Fraction of Cosolvent (XCosolvent) for 2-AdOTs and [2.2.2]-OTs at $90^{\circ} \mathrm{C}$

Table VI: Summary of slopes for $\log \mathbf{k}_{\text {ROTFE }}$ versus Mole Fraction of Cosolvent ( $\mathrm{X}_{\text {cosolvent }}$ ) for 2-AdOTs and [2.2.2]-OTs at $90^{\circ} \mathrm{C}$

Table VII: Summary of Selectivities for the Solvolysis of 2AdOTs and [2.2.2]-OTs in tertiary mixtures of TFE-EtOH and Cosolvent at $90^{\circ} \mathrm{C}$ 


\section{LIST OF FIGURES}

Figure 1: $\quad$ Log $k_{\text {obs }}$ versus Mole Fraction of Cosolvent $\left(\mathrm{X}_{\mathrm{CHC} 13}\right)$ for 2-AdOTs and [2.2.2]-OTs in 80:20 vol.\% of TFEEtOH.

Figure 2: $\quad$ Log $k_{\mathrm{obs}}$ versus Mole Fraction of Cosolvent $\left(\mathrm{X}_{\mathrm{CHCl3}}\right.$ and $\mathrm{X}_{\mathrm{CCl} 4}$ ) for 2-AdOTs and [2.2.2]-OTs in 50:50 vol.\% of TFE-EtOH.

Figure 3: $\quad$ Log $\mathrm{k}_{\mathrm{obs}}$ versus Mole Fraction of Cosolvent $\left(\mathrm{X}_{\mathrm{CHCl}}\right.$ and $\mathrm{X}_{\mathrm{CCl} 4}$ ) for 2-AdOTs and [2.2.2]-OTs in 20:80 vol.\% of TFE-EtOH.

Figure 4: Log kROTFE versus Mole Fraction of Cosolvent $\left(\mathrm{X}_{\mathrm{CHCl}}\right)$ for 2-AdOTs and [2.2.2]-OTs in 80:20 vol.\% of TFEEtOH

Figure 5: Log kROTFE versus Mole Fraction of Cosolvent $\left(\mathrm{X}_{\mathrm{CHC13}}\right.$ and $\mathrm{X}_{\mathrm{CCl} 4}$ ) for 2-AdOTs and [2.2.2]-OTs in 50:50 vol.\% of TFE-EtOH.

Figure 6: Log kROTFE versus Mole Fraction of Cosolvent $\left(\mathrm{X}_{\mathrm{CHCl} 3}\right.$ and $\mathrm{X}_{\mathrm{CCl} / 4}$ ) for 2-AdOTs and [2.2.2]-OTs in 20:80 vol.\% of TFE-EtOH. 


\section{INTRODUCTION}

Nucleophilic substitution reactions in solution were first studied systematically by Hughes and Ingold over 50 years ago. ${ }^{1}$ Their classification of these reactions as either unimolecular, $\mathrm{S}_{\mathrm{N}} 1$, or bimolecular, $\mathrm{S}_{\mathrm{N}} 2$, has formed the basis for subsequent research on this subject. Those reactions where the solvent acts as the nucleophile and appears as a part of the products, are defined as solvolyses reactions.

In the 1950's Winstein proposed that the general mechanism of a solvolysis reaction can be represented by the following ion pair scheme (Scheme 1). ${ }^{2}$

\section{Scheme 1}



Ionization of $\mathrm{RX}$ in a hydroxylic solvent ( $\mathrm{SOH}$ ) results in the formation of an internal ion pair $\left|R^{+} X^{-}\right|$. The internal ion pair, which is enclosed in a cage of solvent molecules, can either collapse back to the starting material (internal return) or further diffuse apart to form a solvent separated ion pair $\mathrm{R}^{+} \| \mathrm{X}^{-}$, where at least one solvent separates the two ions. The solvent separated ion pair can either collapse back to the reactants (external return) or further dissociate to give free ions. 
In a solvolysis reaction any one of the species 3 in Scheme 1 can react with a solvent nucleophile to give the product, R-OS. When a nucleophile attacks the substrate, RX, the rate-determining step is bimolecular and the reaction mechanism is classified as $\mathrm{S}_{\mathrm{N}} 2$. If the rate-determining step occurs before the reaction with solvent nucleophile, the mechanism is classified as $\mathrm{S}_{\mathrm{N}}$ 1. Understanding the mechanistic details in the majority of reactions that appear to be on the borderline of the $\mathrm{SN}_{\mathrm{N}} 1-\mathrm{SN}_{\mathrm{N}} 2$ mechanistic spectrum has been a controversial subject which is still under debate.

Although the Winstein Ion Pair Scheme provides a useful mechanistic framework with which to discuss observed effects such as salt effects ${ }^{2}$, common ion rate depression ${ }^{3}$, product stereochemistry in optically active systems ${ }^{4}$, and equilibration of labeled oxygens in sulfonate and carboxylate leaving groups $\mathrm{s}^{5 \cdot 7}$, the specific role of the solvent in solvolyses reactions is not specified. Solvolytic rates are highly dependent upon the reaction medium. For example, $t$-butyl chloride ( $t$-BuCl) solvolyzes 316,000 times faster in water than it does in ethanol. ${ }^{3}$

Grunwald and Winstein 8,9 developed a linear free-energy relationship (eq. 1), as a mechanistic probe, for determining the extent that any substrate

$$
\log \left(\mathbf{k} / \mathbf{k}_{\mathbf{o}}\right)=\mathbf{m} \mathbf{Y}_{\mathrm{GW}}
$$

of interest undergoes nucleophilic assistance by the solvent. In the Grunwald-Winstein treatment a scale of solvent ionizing power $\left(\mathrm{Y}_{\mathrm{GW}}\right)$ is defined based on the specific rates of solvolysis of $t-\mathrm{BuCl}$ at $25{ }^{\circ} \mathrm{C}$. In eq. 1 , 
$k$ represents the specific rate of solvolysis in the solvent under consideration and $\mathrm{k}_{0}$ refers to the rate in $80 \%$ aqueous ethanol. For $\boldsymbol{t}-\mathrm{BuCl}, \mathrm{m}$ is defined as unity and represents the sensitivity of the solvolysis to changes in solvent ionizing power. For substrates other than $t$-BuCl, the $\mathrm{m}$ value is the slope of a linear correlation between the $\log \left(k / k_{0}\right)$ and $Y_{G W}$. The magnitude of $m$ is used as a mechanistic criterion for unimolecular $\mathrm{SN}_{\mathrm{N}}(\mathrm{m}=1)$ or bimolecular $\mathrm{SN}_{\mathrm{N}}(\mathrm{m} \ll 1)$ reaction.

$\mathrm{Y}_{\mathrm{GW}}$ values were determined for a variety of binary solvent systems, by using eq. 1 with $t$-BuCl as the standard substrate. Correlation of solvolytic rates for other substrates revealed that separate lines for each different solvent pair (dispersion) were generally observed. This led to the conclusion that $\mathrm{m}$ and $\mathrm{Y}$ are not linearly independent and the substrate parameter $m$ is solvent dependent. Nevertheless, the Grunwald-Winstein $Y$ scale was deemed an adequate tool for probing nucleophilic assistance. However, Schleyer's ${ }^{3}$ investigations of rearrangements during the solvolysis of 2-exo-norbornyl tosylate led him to suspect that nucleophilic solvent assistance is more general than had previously been thought, and that it might even be significant in the solvolysis of $t-\mathrm{BuCl} .{ }^{10}$ In fact, $t-\mathrm{BuCl}$ was assumed to solvolyze without any nucleophilic solvent assistance in the original Grunwald-Winstein treatment.

Schleyer ${ }^{11}$ proposed the secondary 2 -adamantyl tosylate (2-AdOTs) system as a model that cannot undergo rearrangement or back side attack by the solvent. In choosing 2-AdOTs as a model compound for solvolysis of secondary substrates, Bentley and Schleyer ${ }^{12,14}$ assumed that 2-AdOTs 
solvolyzed with neither appreciable nucleophilic solvent assistance nor significant internal ion pair return ${ }^{6}$, as required by the definition of $Y$. They assumed that heterolysis of $\mathrm{C}-\mathrm{X}$ bond is the rate-determining step and that solvent molecules do not participate as nucleophiles at this stage. Bunnett and Paradisi ${ }^{7}$ found that internal ion pair return does occur as evidenced by the rate of $18 \mathrm{O}$ equilibration in solvolysis of 2 -adamantyl benzenesulfonates (2-AdOBs) in three solvents of differing nucleophilicity (80\% aqueous ethanol, TFE, and acetic acid), where more than half of the intimate ion pairs undergo internal return. They found that the rate of $18 \mathrm{O}$ equilibration was faster than the rate of product formation. Shiner ${ }^{15,16}$ and Maskill ${ }^{17}$ argued that the transformation of intimate to solvent-separated ion pair is largely the rate-determining step, based on the solvolysis of cyclopentyl $p$-bromobenzenesulfonates in eight differrent solvents and on the solvolysis of secalkyl azoxytosylates respectively.

A number of $Y_{X}{ }^{18-20}$ scales based upon solvolyses of 1-adamantyl (1AdX) and 2-adamantyl substrates (2-AdX) have been set up to account for differential electrophilic assistance amongst various leaving groups. Solvolyses of 2-AdOTs at $25{ }^{\circ} \mathrm{C}$ were chosen to define a $\mathrm{Y}_{\mathrm{OTs}}{ }^{13}$ scale of solvent ionizing power based on the eq. 2 for tosylates.

$$
\log \left(\mathbf{k} / \mathbf{k}_{\mathbf{o}}\right)_{A d X}=\mathbf{Y}_{\mathbf{X}}
$$

Many other $\mathrm{Y}^{21,22}$ scales have been proposed including a $\mathrm{Y}_{\mathrm{OMs}}$ scale for mesylates and a $\mathrm{Y}_{\mathrm{OSO}_{2}} \mathrm{CF}_{3}$ scale for 2-adamantyl triflates (2-AdOTf). The $\mathrm{Y}_{\mathrm{X}}{ }^{23.24}$ values derived from solvolyses of other sulfonates, such as tresylates 
(2-AdOSO ${ }_{2} \mathrm{CH}_{2} \mathrm{CF}_{3}$ ), pentafluorobenzenesulfonates (YPFB), and 2AdOSO $_{2} \mathrm{CH}_{2} \mathrm{CH}_{2} \mathrm{NMe}_{3}{ }^{+}$were very similar to $\mathrm{Y}_{\mathrm{OT}}$. Additional $\mathrm{Y}^{25-26}$ scales have been developed based on the solvolysis of ferrocenylmethyl and $\alpha$ ferrocenylethyl acetates $\left(\mathrm{Y}_{\mathrm{OAc}}\right)$ and on the solvolysis of 2-phenyl-2-adamantyl $p$-nitrobenzoate $\left(\mathrm{Y}_{\mathrm{BnOPNB}}\right)$.

The analysis of product distributions ${ }^{27-29}$ is also used to assess the role of solvent in solvolyses reactions. Since the product forming step presumably occurs after the rate-determining step, the analysis of product ratios provides information about the nature of the product forming intermediate. Product distributions usually are evaluated in terms of selectivity, that is, the ratio of the second-order rates of product formation as defined in eq. 3.

$$
\mathrm{S}=\frac{\mathbf{k}_{\mathrm{S} 1}}{\mathbf{k}_{\mathrm{S} 2}}=\frac{\left[\mathrm{ROS}_{1}\right]\left[\mathrm{SOH}_{2}\right]}{\left[\mathrm{ROS}_{2}\right]\left[\mathrm{SOH}_{1}\right]}
$$

In a binary mixture of hydroxylic solvents, $\mathrm{SOH}_{1}$ and $\mathrm{SOH}_{2}$, the selectivity (S) is a measure of the dominance of a solvent nucleophile in a reaction product. In eq. $3, \mathrm{k}_{\mathrm{S} 1}$ and $\mathrm{k}_{\mathrm{S} 2}$ are the second-order rate constants for the formation of products $\operatorname{ROS}_{1}$ and $\mathrm{ROS}_{2}$ respectively, which result from the bimolecular reaction between a solvent molecule and one of the cationoid species in Scheme 1. If the lifetime of the product forming intermediate is long enough, then it is expected that reaction with the better solvent nucleophile will be preferred. Thus if $\mathrm{SOH}_{1}$ is a better nucleophile than $\mathrm{SOH}_{2}$, a selectivity value greater than unity will be observed. A selectivity 
value less than unity indicates that the poorer nucleophile is preferred, and a value of unity represents a non selective model. Contrary to the prediction of the Grunwald-Winstein mechanism, in adamantyl systems ${ }^{28}$ observed selectivities are usually inverted.

Harris and his collaborators ${ }^{30}$ observed inverted selectivities for the solvolysis of a series of 2-adamantyl arenesulfonates in $\mathrm{EtOH}-\mathrm{H}_{2} \mathrm{O}$ mixtures, where water apparently exhibits greater nucleophilicity than EtOH. This phenomenon was attributed to the ability of the water to form two hydrogen bonds with two oxygen atoms of an arenesulfonate leaving group in a solvent separated ion pair, as shown below:

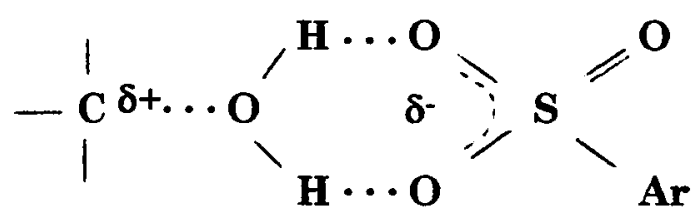

This interpretation was criticized by Pross 28 on the basis that even 1adamantyl, 2-adamantyl chloride, and exo-2-norbornyl chloride, to which no such double hydrogen bonding is expected, showed inverted selectivities. Pross claimed that the bulkiness of EtOH and the higher acidity of the water were possible causes.

Ando $^{31}$ and Tsukamoto determined selectivities for the solvolysis of 1adamantyl and 2-adamantyl derivatives in 50\% (v/v) EtOH-TFE mixtures and observed that TFE was favored over EtOH in the formation of the products in most cases, even though EtOH is a thousand times better 
nucleophile than TFE. They assumed that products were formed by front side collapse of solvent separated ion pairs, where a TFE-separated ion pair was more stable than a EtOH-separated ion pair. They concluded that electrophilicity is an important factor in determining the selectivity.

Rappoport ${ }^{32}$ reported variable selectivities for the solvolysis of 1-AdBr in EtOH-TFE and $\mathrm{H}_{2} \mathrm{O}-\mathrm{TFE}$ mixtures. For EtOH-TFE case, TFE was favored over EtOH at low $[\mathrm{X}(\mathrm{TFE})<0.35]$ and high $[\mathrm{X}(\mathrm{TFE})>0.65]$ concentrations while $\mathrm{EtOH}$ was favored at the intermediate concentrations. For solvolysis in $\mathrm{H}_{2} \mathrm{O}-\mathrm{TFE}$ mixtures it was found that TFE was favored over $\mathrm{H}_{2} \mathrm{O}$ at $[\mathrm{X}(\mathrm{TFE})<0.29]$ and $\mathrm{H}_{2} \mathrm{O}$ was favored at $[\mathrm{X}(\mathrm{TFE})>0.29]$ ! It seemed that selectivities were composition dependent and one possible explanation was that the solvent effect on the ionization rate of $1-\mathbf{A d B r}$ was composed of a general dielectric constant effect and electrophilic assistance via hydrogen bonding to the leaving group.

McManus $^{33}$ reported a study of 1-AdBr solvolysis in several binary protic solvents. He accounted for the observed "abnormal" selectivities in terms of the varying acidity and molecular volume of the solvent.

Kevill ${ }^{34}$ found that the selectivities in solvolysis-decomposition of 1 adamantyl chloroformate (1-ADOCOCl) in EtOH-TFE, are very similar to those observed in conventional solvolyses of 1-adamantyl derivatives. He suggested that 1-Ad+ ${ }^{+} \mathrm{Cl}^{-}$ion pair intermediates are formed, almost identical in structure to those existing as intermediates in 1-AdCl solvolyses, and that 
they either collapse (internal return) or proceed to solvolysis products via the solvent separated ion pair.

Inverted selectivities were observed by Ferla ${ }^{35}$ and Sluka ${ }^{36}$ in the solvolysis of 1- and 2-adamantyl tosylates (1-AdOTs and 2-AdOTs) and 1bicyclo[2.2.2]octanyl tosylates ([2.2.2]-OTs) in EtOH-TFE media. Since the selectivity behavior cannot be rationalized in terms of solvent parameters such as ionizing power and nucleophilicity, an alternative treatment was utilized to explain the data. The solvolytic rates were analyzed in terms of solvent composition (mole fraction). The fact that the slopes of $\log \mathrm{k}_{\mathrm{obs}} \mathrm{vs}$. $\mathrm{X}_{\mathrm{TFE}}$ correlation were similar for the two bridgehead substrates, but greater than that for 2-AdOTs, was interpreted as evidence of a nucleophilic solvent assistance component in the observed rates of 2-AdOTs solvolysis. The inverted selectivity behavior was related to the enhanced acidity of TFE over $\mathrm{EtOH}$, and also correlated to changes in solvent viscocity. It was suggested that the rate-determining step involves the diffusional separation of specifically solvated internal ion pairs, that lead directly to solvolysis products. Because the lifetimes of the intermediates are less than or equal to the diffusional limit of the medium, the solvent pool in the vicinity of a reacting ion pair must necessarily be determined in the ground state, that is, by a solvent sorting phenomenon. Similar selectivity behavior, albeit less pronounced, was reported ${ }^{37}$ for the solvolysis of 1-adamantyl iodide (1-AdI) in EtOH-TFE mixture.

Nauka ${ }^{38}$ determined solvolysis rates and product distributions of 1 adamantyl mesylate (1-AdOMs), 2-AdOTs, and [2.2.2]-OTs in ternary 
mixtures of EtOH-TFE (50/50 volume percent) and a non-solvolytic cosolvent such as $\mathrm{CHCl}_{3}, \mathrm{CCl}_{4}$, acetone or hexane. In this exploratory work, inverted selectivities were observed in all cases except for variable selectivities in acetone media. For 2-AdOTs, the selectivity values $\left(\mathrm{k}_{\mathrm{TFE}} / \mathrm{k}_{\mathrm{EtOH}}\right)$ decreased with decreasing the mole fraction of acetone, and for acetone concentrations between 0.18 and 0.95 the selectivity values were less than one. These results were discussed in terms of the TFE's ability to form hydrogen bonds with both the leaving group and the cosolvent.

In the previous studies by Sluka ${ }^{36}$, Ferla $^{35}$ and Nauka ${ }^{38}$, it was suggested that for the solvolyses of bridgehead systems, the variation of the product distribution with medium composition was related to the solvent viscosity, which in turn, is inversely proportional to the diffusional properties. Observed inverted selectivities indicated that TFE was the preferred nucleophile even at TFE concentrations as low as 0.02 mole fraction relative to EtOH. Similar behavior was observed in 50:50 (volume percent TFE-EtOH)-cosolvent mixtures. We were interested in determining whether similar trends would be observed at higher (80:20) and lower (20:80) TFE-EtOH ratios in the ternary solvent mixtures.

Thus, the objective of this research is to extend Nauka's studies in order to include three TFE-EtOH compositions $(80 / 20,50 / 50,20 / 80$ volume percent), and to increase the number of ternary compositions at which rates and product distributions are measured. Two cosolvents $\left(\mathrm{CHCl}_{3}\right.$ and $\left.\mathrm{CCl}_{4}\right)$ were chosen as the most "well-behaved" non-reactive cosolvents in Nauka's work. As substrates, we selected [2.2.2]-OTs and 2-AdOTs because of their 
obvious structural differences (tertiary and bridgehead vs. secondary and rear-side accessible), and because they have comparable reactivity at $90{ }^{\circ} \mathrm{C}$. The choice of the reacting hydroxylic solvents (TFE and EtOH) is based on existing extensive data. ${ }^{35-38} \mathrm{TFE}$ and $\mathrm{EtOH}$ are both primary alcohols with similar molecular volumes and dielectric constants. However these solvents have significantly different nucleophilicities, ionizing power (Y), and acidities. TFE is approximate 1000 times less nucleophilic than $\mathrm{EtOH}^{40}$ but is a better ionizing solvent and a stronger acid than EtOH by over three orders of magnitude. Accordingly, we wish to report rates and product distributions for the solvolysis of [2.2.2]-OTs and 2-AdOTs in ternary mixtures of TFE-EtOH and $\mathrm{CHCl}_{3}$ or $\mathrm{CCl}_{4}$.

\section{EXPERIMENTAL SECTION}

Infrared spectra were recorded with a Perkin-Elmer FTIR-1620 spectrophotometer. A Beckman model 25 uv-vis spectrophotometer was used for ultraviolet spectra to follow the kinetics. Melting points were determined with a digital melting point apparatus (Electrothermal IA 9200) and they are uncorrected. Gas chromatographic and mass spectroscopic data were obtained on a Finnigan 1020 GC/MS (DB-5 x 30 meter column).

Synthesis of 1-Bicyclo[2.2.2]-octanyl Tosylate. 1-Bicyclo[2.2.2]octanol $(0.49 \mathrm{~g}, 3.9 \mathrm{mmol}), 5 \mathrm{~mL}$ of dry pyridine $(\mathrm{BaO})$ and $p$-toluenesulfonyl chloride $\left(1.3 \mathrm{~g}, 67 \mathrm{mmol}, \mathrm{mp} 66.8-67.5{ }^{\circ} \mathrm{C}\right)$ were sealed in an ampule, and kept at $40{ }^{\circ} \mathrm{C}$ for $95 \mathrm{hrs}$. After cooling, the oily-brown solution was poured 
into ice-water $(30 \mathrm{~mL})$. The precipitated solid tosylate was extracted with anhydrous ethyl ether $(30 \mathrm{~mL})$. The ether solution was washed with $5 \%$ aq $\mathrm{HCl}(3 \times 20 \mathrm{~mL}), 5 \%$ aq $\mathrm{NaHCO}_{3}(3 \times 20 \mathrm{~mL})$, and dried $\left(\mathrm{MgSO}_{4}\right)$. The ether solution was vacumm filtered through a celite mat, and the solvent was removed under reduce pressure giving $0.75 \mathrm{~g}$, (70\%) of crude tosylate. Recrystallization from petroleum ether $(30-60)$ at $0{ }^{\circ} \mathrm{C}$ gave pure white [2.2.2]-OTs: mp 62.3-63.7 ${ }^{\circ} \mathrm{C}$ (lit. $35 \mathrm{mp} 65^{\circ} \mathrm{C}$ ). IR (nujol) 2924 (Ar-H), 1597 and $1460(\mathrm{Ar}), 1333$ (asym. $\mathrm{O}=\mathrm{S}=0), 1186(\mathrm{sym} . \mathrm{O}=\mathrm{S}=0) \mathrm{cm}^{-1}$.

Synthesis of 2-Adamantyl Tosylate. 2-Adamantanol $(1.0 \mathrm{~g}, 6.5$ mmol), $10 \mathrm{~mL}$ of dry pyridine (BaO), and $p$-toluenesulfonyl chloride $(2.5 \mathrm{~g}, 13$ mmol) were sealed in an ampule and kept at room temperature for 2 days. 2AdOTs was obtained in $85 \%$ yield using the same procedure as that for [2.2.2]-OTs, mp 82.8-83.2 ${ }^{\circ} \mathrm{C}$ (lit. 17 82.7-83.7 ${ }^{\circ} \mathrm{C}$ ). IR (nujol) 2923 (Ar-H), 1594 and 1459 (Ar) 1328 (asym. $\mathrm{O}=\mathrm{S}=0), 1168(\mathrm{sym} . \mathrm{O}=\mathrm{S}=0) \mathrm{cm}^{-1}$.

Solvent purification. Dry TFE and EtOH were each prepared by refluxing for 24 hours over $4 \mathrm{~A}$ molecular sieves which had been dried in an oven at $100{ }^{\circ} \mathrm{C}$ for several days before use. The solvent was subsequently distilled and the first few drops of the distillate at $73^{\circ} \mathrm{C}$ for TFE, and at $78{ }^{\circ} \mathrm{C}$ for $\mathrm{EtOH}$ were discarded. Reagent grade $\mathrm{CHCl}_{3}$ and $\mathrm{CCl}_{4}$ were obtained from commercial sources, and used without further purification. 
Solvolysis rate studies.

Kinetic studies for 2-AdOTs and [2.2.2]-OTs were performed in a ternary solvent mixture containing $x \%$ of a TFE-EtOH mixture at 80/20, $50 / 50$ or $20 / 80$ volume percent respectively, and a third non-reactive cosolvent $\mathrm{CHCl}_{3}$ or $\mathrm{CCl}_{4}$, at five volume percent compositions $\{(100-\mathrm{x})$, where $x=80,70,50,30,20\}$. The actual procedure is described below for [2.2.2]OTs in TFE-EtOH (80:20) and varying amounts of $\mathrm{CHCl}_{3}$. Analogous procedures were used in all other cases.

Solvolysis rate studies for [2.2.2]-OTs in 80\% TFE-EtOH (80:20) and $20 \% \mathrm{CHCl}_{3}$. [2.2.2]-OTs was added to a mixture of TFE-EtOH (80:20 volume percent) to make a $2 \mathrm{mM}$ stock solution. A second $2 \mathrm{mM}$ stock solution of [2.2.2]-OTs in $\mathrm{CHCl}_{3}$ prepared. The alcohol and cosolvent stock solution were combined in a ratio of $4: 1$ by volume. Approximately $2 \mathrm{~mL}$ aliquots of the resulting mixture were sealed in $2 \mathrm{~mL}$ ampules and solvolyzed in an oil bath at $90{ }^{\circ} \mathrm{C}$. Individual ampules were removed at specific time intervals, labeled and stored in a refrigerator. At the end of the run, the samples were allowed to warm at room temperature and the tosylate concentration was determined spectrophotometrically in the uv by measuring the optical density of the sample at $263 \mathrm{~nm}$. This procedure was repeated for mixtures of TFE-EtOH (80:20) and $\mathrm{CHCl}_{3}$ in volule ratios of $\mathrm{x}=70,50,30$, and 20 volume percent of the alcohol stock solution and $(100-x)$ volume percent of $\mathrm{CHCl} 3$. 
The reactions were followed for about 3 half-lives for the slower cases and up to $\mathbf{1 0}$ half-lives for the faster rates. Measured infinity absorbances were stable, and agreed with calculated values, within experimental error, in all cases. Rate constants were calculated by non-linear least squares method (LSKIN) ${ }^{39}$, with calculated standard deviations in $\mathrm{k}$ less than $\pm 3 \%$. Rates for 2-AdOTs and [2.2.2]-OTs in 80:20 binary TFE-EtOH mixtures in $\mathrm{CCl}_{4}$ could not be measured due to the immiscibility of $\mathrm{CCl}_{4}$ cosolvent.

\section{Product studies.}

Product studies for the solvolysis of 2-AdOTs and [2.2.2]-OTs were performed in ternary solvent mixtures exactly analogous to those used in the kinetic studies. Each product study was performed in duplicate at $90 \pm 0.05$ ${ }^{\circ} \mathrm{C}$ on independently prepared samples. Ternary mixtures were prepared, containing $x \%$ of TFE-EtOH at $80 / 20,50 / 50$, or $20 / 80$ volume percent respectively, and the non-reactive cosolvent, $\mathrm{CHCl}_{3}$ or $\mathrm{CCl}_{4}$, at five volume percent compositions $\{(100-x)$, where $x=80,70,50,30,20\}$. A sample procedure is described below for [2.2.2]-OTs in TFE-EtOH (80:20) and varying amounts of $\mathrm{CHCl}_{3}$. Analogous procedures were used in all other cases.

General Procedure for Product Studies of [2.2.2]-OTs in TFEEtOH Plus a $\mathrm{CHCl}_{3}$ or $\mathrm{CCl}_{4}$ Cosolvent. Stock solutions of [2.2.2]-OTs in TFE-EtOH and cosolvents were prepared as described for the kinetic studies, except that each solution was buffered with ca. $2 \mathrm{mM}$ of 2,4,6-trimethyl pyridine. Aliquots (ca. $2 \mathrm{~mL}$ ) of the resulting solutions were placed in $2 \mathrm{~mL}$ 
ampules, sealed and solvolyzed for 5 to 10 half-lives in an oil bath at $90 \pm$ $0.05{ }^{\circ} \mathrm{C}$. As a standard, the alcohol stock solutions also were solvolyzed without the presence of cosolvent. The samples were analyzed and quantitated by the GC/MS, by using selected ion monitoring of only the base peak in the mass spectrum of each product. Since the ratio of the two alcohols (TFE-EtOH) was kept constant in all three TFE-EtOH-cosolvent compositions, the reported percents of the ether products were not sensitivity corrected. At least three injections per sample were performed with reproducibility to within one percent or less.

\section{TREATMENT OF THE DATA}

Throughout the following discussion, the mole fraction of a solvent component, such as TFE, refers to its concentration relative to the other solvent components in the medium. The product distribution is expressed in terms of the mole fraction of the trifluoroethyl ether (XROTFE) product relative to that of the ethyl ether $\left(\mathrm{X}_{\mathrm{ROE}}\right)$ solvolysis product. Selectivities for the TFE-EtOH solvent system are calculated by using the eq. 4 , where $\mathrm{k}_{\mathrm{t}}$ and $k_{e}$ are the second-order rate order constants for the formation of the ROTFE and ROEt products respectively. In other words, selectivity values greater than unity actually are "inverted" with respect to treatments where the rate of formation of the product resulting from the better nucleophile is expressed in the numerator. 


$$
\mathrm{S}=\frac{\mathrm{k}_{\mathrm{t}}}{\mathrm{k}_{\mathrm{e}}}=\frac{\left[\mathrm{X}_{\mathrm{ROTFE}}\right]\left[\mathrm{X}_{\mathrm{EtOH}}\right]}{\left[\mathrm{X}_{\mathrm{ROEt}}\right]\left[\mathrm{X}_{\mathrm{TFE}}\right]}
$$

First-order rate constants for the formation of the respective products ( $\mathrm{k}_{\mathrm{ROTFE}}$ and $\mathrm{k}_{\mathrm{ROEt}}$ ) are calculated using eq. 5 , where $\mathrm{k}_{\mathrm{ROS}}$ is the desired rate constant, $\mathrm{k}_{\mathrm{obs}}$ is the observed reaction rate and $\mathrm{X}_{\mathrm{ROS}}$ is the mole fraction of product formed.

$$
\mathrm{k}_{\mathrm{ROS}}=\left[\left(\mathrm{X}_{\mathrm{ROTFE}}\right)\right] \mathrm{k}_{\mathrm{obs}}
$$

Second-order rate constants for the formation of the respective products $\left(\mathrm{k}_{\mathrm{t}}\right.$ and $\mathrm{k}_{\mathrm{e}}$ ) are calculated by dividing the first-order rate of product formation (eq. 5) by the molar concentration of the particular solvent component, as shown for $k_{t}$ in eq. 6 .

$$
\mathrm{k}_{\mathrm{t}}=\frac{\mathrm{k}_{\mathrm{ROTFE}}}{[\mathrm{TFE}]}
$$

\section{RESULTS}

Data for the solvent composition, the observed products and the reaction rates along with the calculated first-order and second-order rates of product formation, and the calculated selectivities for the solvolysis of 2AdOTs in $\mathrm{CHCl}_{3}$ containing varying amounts of 80:20, 50:50 and 20:80 volume percent TFE:EtOH are listed in Table I. Corresponding data for 2AdOTs in $\mathrm{CCl}_{4}$ cosolvent are listed in Table II. Similarly, Tables III and IV 
contain the results for the solvolyses of [2.2.2]-OTs in $\mathrm{CHCl}_{3}$ and $\mathrm{CCl}_{4}$ respectively.

Kinetic studies. The observed solvolysis rates ( $\mathrm{k}_{\mathrm{obs}}$ ) of 2-AdOTs in TFE-EtOH/CHCl3 media at $90{ }^{\circ} \mathrm{C}$ are listed in Table I, and those measured in $\mathrm{CCl}_{4}$ cosolvent are presented in Table II. The corresponding data for [2.2.2]-OTs in the ternary solvent mixtures are shown in Tables III and IV respectively. Clean first-order kinetics were observed in all cases, and the rate decreases as the TFE content of the medium decreases. This is consistant with other rate data for 2-AdOTs and [2.2.2]-OTs reported by Sluka ${ }^{36}$ and Ferla ${ }^{35}$. In particular, the observed rates $\left(38 \times 10^{-5} \mathrm{sec}^{-1}\right.$ and $5.25 \times 10^{-5} \mathrm{sec}^{-1}$ ) for [2.2.2]-OTs in 50:50 and 20:80 volume percent of TFEEtOH respectively are in excellent agreement with the values reported by Sluka (37 $\times 10^{-5} \mathrm{sec}^{-1}$ and $5.26 \times 10^{-5} \mathrm{sec}^{-1}$ ), measured under the same conditions. The rates for 2-AdOTs and [2.2.2]-OTs in 50:50 volume percent of TFE-EtOH (1:1) and $\mathrm{CCl}_{4}$ respectively $\left(7.8 \times 10^{-4} \mathrm{sec}^{-1}\right.$ and $3.6 \times 10^{-5}$ $\left.\mathrm{sec}^{-1}\right)$ are also in agreement with those reported by Nauka ${ }^{38}\left(7.4 \times 10^{-4} \mathrm{sec}^{-1}\right.$ and $2.4 \times 10^{-5} \mathrm{sec}^{-1}$ ), within experimental error.

Logarithms of the observed rate constants for 2-AdOTs and [2.2.2]OTs in TFE-EtOH (80:20) mixtures are plotted versus the mole fraction of the cosolvent in Figure 1. Similar plots for the TFE-EtOH (50:50) and (20:80) data are shown in Figures 2 and 3 respectively. Excellent linear correlations of the data were obtained, with correlation coefficients of 0.999 in all cases. The results of the correlations are summarized in Table V. Not surprising is the fact that the rates decrease with increasing cosolvent 
concentration, and are dependent on the nature of the cosolvent. Within experimental error, the rates for both substrates are slower in $\mathrm{CCl}_{4}$ than in $\mathrm{CHCl}_{3}$, at a particular cosolvent composition, with the biggest difference in 20:80 volume percent in TFE-EtOH. However, the range of the slope for 2AdOTs is between $1.25 \pm 0.01$ and $2.44 \pm 0.07$ for $\mathrm{CHCl}_{3}$, and between $1.57 \pm$ 0.03 and $2.13 \pm 0.05$ for $\mathrm{CCl}_{4}$, whereas the range of the slope for [2.2.2]-OTs is between $1.69 \pm 0.05$ and $2.56 \pm 0.06$ for $\mathrm{CHCl}_{3}$ and between $2.00 \pm 0.04$ and $2.53 \pm 0.04$ for $\mathrm{CCl}_{4}$. In general, the slopes for [2.2.2]-OTs are steeper than those for the 2-AdOTs in all TFE-EtOH-cosolvent compositions as shown in Table V.

Product studies. Product studies were performed in duplicate at $\mathbf{9 0}$ ${ }^{\circ} \mathrm{C}$. The normalized values of the observed TFE-ether products (XROTFE) are listed in Tables I-IV, as described above for the $\mathbf{k}_{0}$ obs data. The $\mathrm{X}_{\mathrm{ROTFE}}$ value observed for 2-AdOTs (52.4\% AdOTFE) at $\mathrm{X}_{\mathrm{TFE}}=\mathbf{0 . 4 5}$ (in the absence of cosolvent) is exactly the same with the one reported by Ando. 31 Values observed for 2-AdOTs $\mathrm{X}_{\mathrm{ROTFE}}=0.58$ at $\mathrm{X}_{\mathrm{TFE}}=0.25 ; \mathrm{X}_{\mathrm{ROTFE}}=0.56$ at $\left.\mathrm{X}_{\mathrm{TFE}}=0.27\right)$ in the presence of $\mathrm{CHCl}_{3}$ and $\mathrm{CCl}_{4}$ respectively are in good agreement with those of Nauka $\left(\mathrm{X}_{\mathrm{ROTFE}}=0.59\right.$ at $\mathrm{X}_{\mathrm{TFE}}=0.26 ; \mathrm{X}_{\mathrm{ROTFE}}=$ 0.60 at $\left.\mathrm{X}_{\mathrm{TFE}}=0.24\right)$. Calculated first-order $\left(\mathrm{k}_{\mathrm{ROTFE}}, \mathrm{k}_{\mathrm{ROEt}}\right)$ and secondorder $\left(k_{t}, k_{e}\right)$ rates of the product formation also are listed in Tables I-IV along with the corresponding selectivities (eq. 3).

The observed correlation between the mole fraction of the cosolvent $\left(\mathrm{X}_{\mathrm{CHCl}_{3}}\right.$ or $\left.\mathrm{X}_{\mathrm{CCl}_{4}}\right)$ and the logarithm of the first-order rate constants for product formation (log $\mathrm{k}_{\mathrm{ROTFE}}$ ) are shown in Figures 4,5 , and 6 . The range 
of the slopes for the solvolysis of 2-AdOTs in $\mathrm{CHCl}_{3}$ is between $1.06 \pm 0.01$ and $2.37 \pm 0.06$, and in $\mathrm{CCl}_{4}$ is from $1.39 \pm 0.04$ to $2.06 \pm 0.05$. For the solvolysis of [2.2.2]-OTs in $\mathrm{CHCl}_{3}$ is between $1.34 \pm 0.04$ and $2.55 \pm 0.06$, and in $\mathrm{CCl}_{4}$ is from $1.91 \pm 0.04$ to $2.48 \pm 0.03$. Again, results are similar to those obtained in previous work. 35.38 The slopes for [2.2.2]-OTs are steeper than those for 2-AdOTs, and there is a small difference in the slopes for $\mathrm{CHCl}_{3}$ and $\mathrm{CCl}_{4}$, as shown in Table VI. The second-order rate data $\left(\mathrm{k}_{\mathrm{t}}, \mathrm{k}_{\mathrm{e}}\right)$ does not correlate well with cosolvent composition. While some $\log k$ versus cosolvent plots (not shown) are linear, others show significant scatter and/or curvature. This is probably due to the greater experimental errors which are composites resulting from mixing the solvents, and determining both $\mathrm{k}_{\mathrm{obs}}$ in the UV as well as the product compositions obtained by GC/MS.

Greater selectivity values for [2.2.2]-OTs than for 2-AdOTs are observed at any set of comparable compositions, and the values increase with decreasing TFE content io the medium, as shown in Table VII.

\section{DISCUSSION}

Kinetic studies. Reaction rates of 2-AdOTs in ternary mixtures of TFE-EtOH and cosolvent are approximately 10 to 100 times faster in 80/20 volume percent TFE-EtOH than in 50/50 and 20/80 volume percent of TFEEtOH respectively. The greater the amount of TFE in the alcohol mixture, the faster is the reaction rate. Presumably, this is due to the greater acidity of TFE and, hence, its ability to better solvate the leaving group by forming 
hydrogen bonds with the oxygens' lone pairs of electrons in the sulfonate group.

Logarithms of the observed rate constants $\left(\log \mathrm{k}_{\mathrm{obs}}\right)$ for 2-AdOTs and [2.2.2]-OTs are plotted versus the mole fraction of the cosolvent (Figures 13). All the plots are linear with correlation coefficients $>0.999$. In all cases studied the rates decrease with increasing cosolvent concentration, and greater slopes are observed for the bridgehead [2.2.2]-OTs than for the secondary 2-AdOTs under the same conditions. This behavior is consistent with the fact that [2.2.2]-OTs can react only by a front side attack of the solvent, while 2-AdOTs can react via both front side and back side (SN2) pathways. Similar results 36.37 were reported previously for [2.2.2]-OTs and 2-AdOTs in the absence of cosolvent.

The log rate versus mole fraction plots (Figures 2 and 3) show separate correlations for $\mathrm{CHCl}_{3}$ and $\mathrm{CCl}_{4}$ cosolvents in the case of 50:50 and 20:80 TFE/EtOH-cosolvent mixtures. This behavior is probably not due to the structure of the substrate because the ratio of the slopes is approximately the same for the two substrates in a given medium. In other words, in the 50:50 TFE-EtOH media the ratios of the slopes are approximately 1.1 for both 2-AdOTs and [2.2.2.]-OTs, while in 20:80 TFE-EtOH the ratios are approximately 1.2. This suggests that the observed differences probably result from the polarity differences of the media, and/or from solvation differences by the cosolvent ${ }^{3}$ around the ionic species that are formed in the reaction. These conclusions are supported by the fact that the slope ratios 
increase as the TFE content of the medium decreases, and that the slopes for the less polar $\mathrm{CCl}_{4}$ media are greater than those for $\mathrm{CHCl}_{3}$ in all cases.

Product Studies. If the solvolyses studied here proceed by a limiting mechanism, then according to Winstein Ion Pair Scheme (Scheme 1), it is expected that the product (R-OS) would arise from the solvent separated ion pair or dissociated ions. The omission of a product forming reaction at the intimate ion pair stage is based on the supposition that the anion portion of the intimate ion pair effectively shields the bridged cation from the covalent solvent attack until solvent intrudes on the intimate ion pair to give the solvent separated ion pair. If this is true and the incipient carbocation can reach the solvent separated ion pair stage, then it would be expected that either the intermediate would have a long enough lifetime to select the better nucleophile or that the EtOH intermediate would be favored in terms of leading to a reaction product. In either case, in binary TFE-EtOH media, this would result in the more nucleophilic EtOH being favored over TFE in the product. The selectivity data shown in Table VII clearly indicates inverted selectivities (i.e., TFE-ether products are favored over EtOH-ether products) for every TFE-EtOH/cosolvent composition studied. Apparently, the nucleophilicity of the solvent is not a significant factor in determining selectivity in these ternary solvent mixtures. In other words, if nucleophilicity is the major factor determining the selectivity, then the EtOH-ether product should be the preferred product.

Both the observed rate and the selectivity behavior described above can be accounted for in a relatively simple manner in terms of a reaction 
mechanism involving a rate-determining diffusional separation of specifically solvated internal ion pair intermediates. The proposed mechanism is shown in Scheme 2. This mechanism explains why TFE is favored over EtOH even

\section{Scheme 2}

$$
\begin{gathered}
\mathrm{R}-\mathrm{OTs}+\mathrm{SOH} \underset{\mathrm{k}-1}{\stackrel{\mathrm{k}_{1}}{\longrightarrow}}\left[\mathrm{R}^{+} \mathrm{OTs}^{-}\right] \stackrel{\mathrm{k}_{2}}{\longrightarrow} \mathrm{ROS}+\mathrm{HOTs} \\
\mathrm{k}-1_{1} \gg \mathrm{k}_{1}, \quad \mathrm{k}-1>\mathrm{k}_{2}
\end{gathered}
$$

for the lowest concentration of TFE in the solvent mixture. The second step of the reaction is diffusion controlled. The intermediate does not have long enough lifetime to reach the solvent separated ion pair stage. Thus, the inner solvation pool around the leaving group is determined in the ground state and its composition would be expected to reflect TFE's greater hydrogen bonding ability. This leads to the inverted selectivities which are observed.

The diffusional mechanism also can accomodate Bunnett and Paradisi's data ${ }^{6}$, indicating that internal ion pair return occurs in at least the 2-adamantyl case. Bond rotation is about ten to a hundred times faster than solvent translational motion. Thus, there is ample time for the three sulfonate oxygens of the leaving group to equilibrate before recombination to starting material. Since bond cleavage and rotation are much faster than the diffusional motion of the solvent, the bulk solvent is essentially frozen on the time frame of bond breakage and reformation (internal return). Internal ion pair recombination is faster than the forward diffusional separation of the ions $\left(k_{-1}>k_{2}\right)$ in agreement with the $18 \mathrm{O}$ exchange that Bunnett ${ }^{7}$ observed 
for 2-adamantyl benzenesulfonate. The cationic intermediate, therefore, can either collapse to reform the starting substrate or it can react with whichever solvent nucleophile is present. In other words, events occurring at a rate greater than or equal to diffusion are allowed, and those slower than diffusion are restricted.

Internal return is allowed since it has been shown to occur at a faster rate than solvolysis. Formation of the internal ion pair is allowed since it is formed as a result of bond breakage which occurs on a time scale much faster than bond rotation. The resulting internal ion pair intermediate is enclosed in a TFE rich solvent cage (due to hydrogen bonding effect) from which nucleophilic capture of the carbocation occurs. This accounts for the observed product distributions that show a higher selectivity toward the TFE-ether compared to EtOH-ether. What is not allowed in this time frame, is the formation of solvent separated ion pairs with lifetimes long enough the allow equilibration with the bulk solvent since this would require a cation stable enough to select the better nucleophile.

The above argument integrates a ground state solvation effect and a viscocity/diffusion transition state model. It is based on the pressumption that at the bridgehead tertiary carbon the reaction can take place only from a front side nucleophilic attack on the carbocation. Although Bentley and Schleyer ${ }^{12-14}$ proposed that the secondary 2-AdOTs is restricted to front side nucleophilic attack, the experimental data shown in Tables I-IV and Figures 1-6 (steeper slopes and greater TFE selectivity for [2.2.2]-OTs than for 2AdOTs) suggest that 2-AdOTs is also subject to back side nucleophilic 
attack. In this case, the ground state argument could be applied. There is no preferential solvation of the tosylate moiety in the ground state by TFE for back side nucleophilic attack. A back side attack would favor a transition state involving the better nucleophile, so that there is a $\mathrm{SN}_{\mathrm{N}} 2$ component to the mechanism. This explanation is consistent with the calculated first-order rate constants of product formation ( $\mathrm{k}_{\mathrm{ROTFE}}$ ), and with the observed selectivity values.

Selectivity values for [2.2.2]-OTs are higher than those observed for 2AdOTs in all comparable cases studied here. For 80/20 TFE-EtOH mixtures, the range of selectivity values for [2.2.2]-OTs (Table VII) is about the same as that for 2-AdOTs. But in the case of 50/50, and 20/80 TFE-EtOH mixtures, where less TFE is present, the range in selectivity values for [2.2.2]-OTs is about twice as much as it is for 2-AdOTs. According to reactivity-selectivity relationship, the range in selectivity values for 2AdOTs in 50/50 and 20/80 TFE-EtOH mixtures is expected to be much lower than those in the case of 80/20 TFE-EtOH mixtures as the amount of EtOH in the alcohol mixture increases, since 2-AdOTs is the less reactive so the more selective substrate, but this is not what we observed. The range in selectivity values implies that the reaction is likely to be a combination of both front side and back side nucleophilic attack on the secondary reacting carbon. TFE is favored from the front side while EtOH is favored from the back side, and since the bulk solvent composition in the vicinity of the reaction is different for each TFE-EtOH mixture, it appears that there is no exchange of the solvation shell (rich in TFE) with the bulk solvent during the course of the reaction, in all three TFE-EtOH/cosolvent compositions, so that 
the results from the application of the composite mechanism for 2-AdOTs could be seen on the selectivity values.

\section{CONCLUSIONS}

[2.2.2]-OTs appears to solvolyze in ternary mixtures of TFE-EtOH and a third, nonreactive cosolvent $\left(\mathrm{CHCl}_{3}\right.$ or $\left.\mathrm{CCl}_{4}\right)$ by rate-determining front side nucleophilic attack of solvent on a diffusionally separating internal ion pair. TFE is still the preferred nucleophile even at very low concentrations of TFE in the medium. The same mechanism may apply for 2-AdOTs. Only in this case the formation of the products appears to be a composite of front side and back side nucleophilic attack, resulting in lower selectivity for TFE. The method of diluting the reactive solvents (TFE and EtOH) in a third nonreactive cosolvent appears to be a valuable tool for elucidating the function of the solvent in solvolysis reactions. 


\section{REFERENCES}

1. Ingold, C. K. J. Chem. Soc. 1943, 2745.

2. Winstein, S.; Robinson G. C. J. Chem. Soc. 1958, 175.

3. Lowry, T. and Richardson, K. Mechanism and Theory in Organic Chemistry, Third edition: Harper and Row: New York, 1987, sections $4.1,4.2,4.4 \& 1.1$

4. Allen, A. D.; Kanagasabapathy, V. M.; Tidwel, T. T. J. Am. Chem. Soc. $1985,107,4513$.

5. Goering, H. L.; Levy, J. L. J. Am. Chem. Soc. 1964, 86, 120.

6. Paradisi, C.; Bunnett, J. F. J. Am. Chem. Soc. 1981, 103, 946.

7. Paradisi, C.; Bunnett, J. F. J. Am. Chem. Soc. 1985, 107, 8223.

8. Grunwald, E.; Winstein, S. J. Am. Chem. Soc. 1948, 70, 846.

9. Winstein, S.; Grunwald, E.; Jones, H. W. J. Am. Chem. Soc. 1951, 73, 2700.

10. Schleyer, P.v.R.; Raber, D. J.; Harris, J. M. J. Am. Chem. Soc. 1971, 93, 4829.

11. Raber, D. J.; Bingham, R. C.; Harris, J. M.; Fry, G. L.; Schleyer, P.v.R. J. Am. Chem. Soc. 1970, 101, 5977.

12. Bentley, T. W.; Schleyer, P.v.R. J. Am. Chem. Soc. 1976, 98, 7658.

13. Schadt, F. L.; Bentley, T. W.; Schleyer, P.v.R. J. Am. Chem. Soc. 1976, 98, 7667 .

14. Bentley, T. W.; Bowen, C. T.; Morten, D. H. J. Am. Chem. Soc. 1981, $103,5466$.

15. Shiner, V. J.; Dowd, W.; Fisher, R. D.; Hartshorn, S. R.; Kessick, M. A.; Milakofsky, L.; Rapp, M. W. J. Am. Chem. Soc. 1969, 34, 4838. 
16. Shiner, V. J.; Nollen, D. A.; Humski, K. J. Am. Chem. Soc. 1979, 44, 2108.

17. Maskill, H.; Thompson, J. T.; Wilson, A. A. J. Chem. Soc. Perkin Trans. 1984, 2, 1693.

18. Bentley, T. W.; Carter, G. E.; Roberts, K. J. J. Org. Chem. 1984, 49, 5183.

19. Schleyer, P.v.R.; Bentley, T. W. Tetrahedron Lett. 1974, 2335.

20. Kevill, D. N.; Bahari, M. S.; Anderson, S. W. J. Am. Chem. Soc. 1984, $106,2895$.

21. Bentley, T. W.; Bowen, C. T. J. Chem. Soc. Perkin II, 1978, 557.

22. Bentley, T. W.; Llewellyn, G. Progress in Physical Organic Chemistry, $1990,17,121$.

23. Kevill, D. N.; Bahnke, R. W. Tetrahedron. 1988, 44, 7541.

24. Hawkinson, D. C.; Kevill, D. N. J. Org. Chem. 1988, 53, 3857.

25. Kevill, D. N.; Pinhas A. R. J. Org. Chem. 1993, 58, 197.

26. Liu, K. T.; Chen, H. I.; Chin, C. P. J. Phys. Org. Chem. 1991, 4, 463.

27. Aronovitch, H.; Pross, A. Tetrahedron Lett. 1977, 31, 2729.

28. Karton, Y.; Pross, A. J. Chem. Soc. Perkin Trans. 1978, 2, 595.

29. Pross, A.; Aronovitch, H.; Koren, R. J. Chem. Soc. Perkin Trans. 1978, $2,197$.

30. Harris, J. M.; Becker, A.; Fagan, J. F.; Walden, F. A. J. Am. Chem. Soc. 1974, 96, 4484.

31. Ando, T.; Tsukamoto, S. I. Tetrahedron Lett. 1977, 32, 2776.

32. Kaspi, J.; Rappoport, Z. J. Am. Chem. Soc. 1980, 102, 3829.

33. McManus, S. P.; Zutaut S. E. Tetrahedron Lett. 1984, 27, 2859. 
34. Kevill, D. N.; Kyong, J. B.; Weitl, F. L.; J. Org. Chem. 1990, 55, 4304.

35. Ferla, S. W. Master Thesis, San Jose State University, 1990.

36. Sluka, J. P. Master Thesis, San Jose State University, 1982.

37. Hague, R. A. Master Thesis, San Jose State University, 1987.

38. Nauka, E. F. Master Thesis, San Jose State University, 1994.

39. Computer Program by Selter, G. A.; San Jose State University.

40. Trahanovsky, W. S.; Doyle, M. P. Tetrahedron Lett. 1968, 18, 2155. 


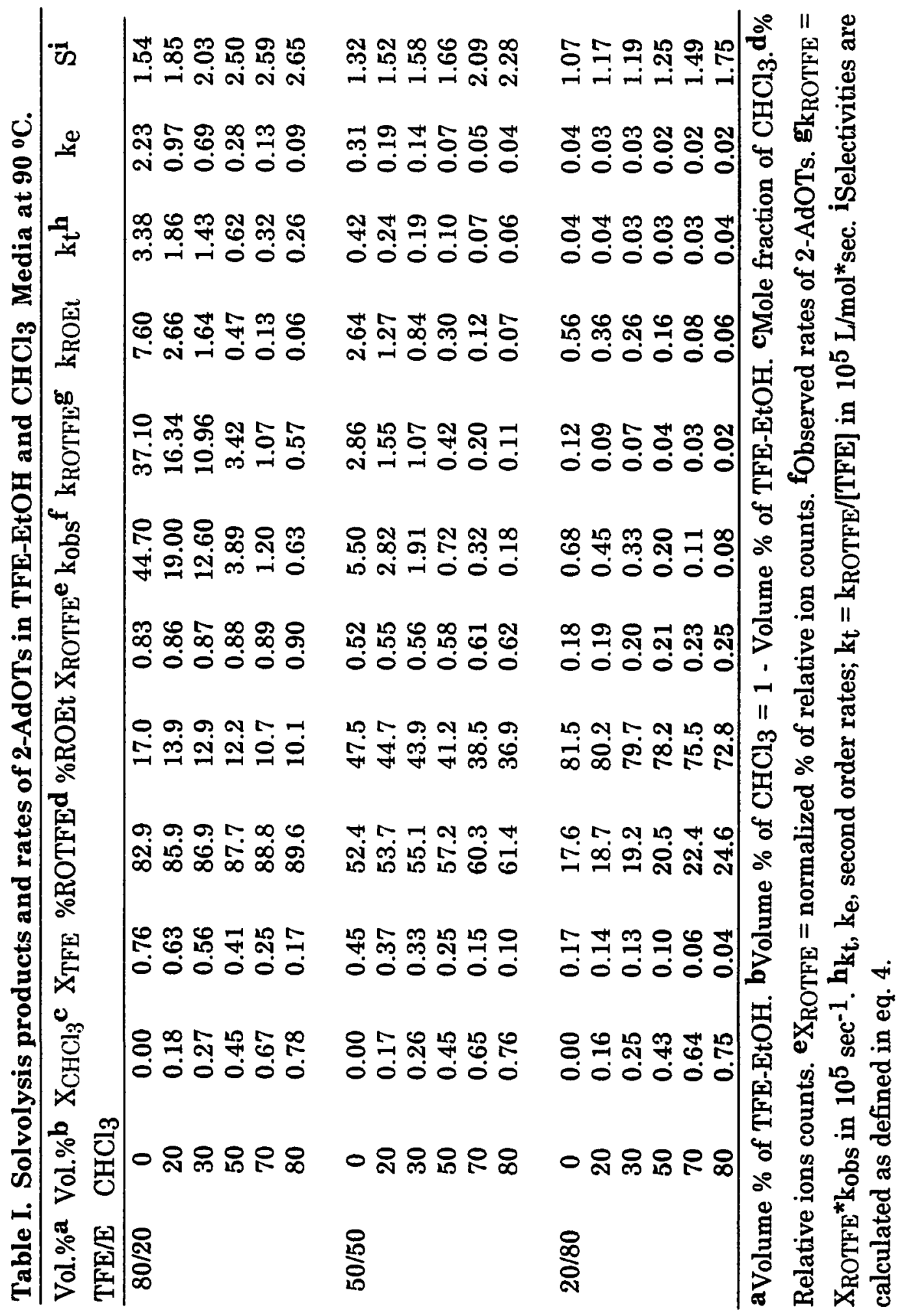




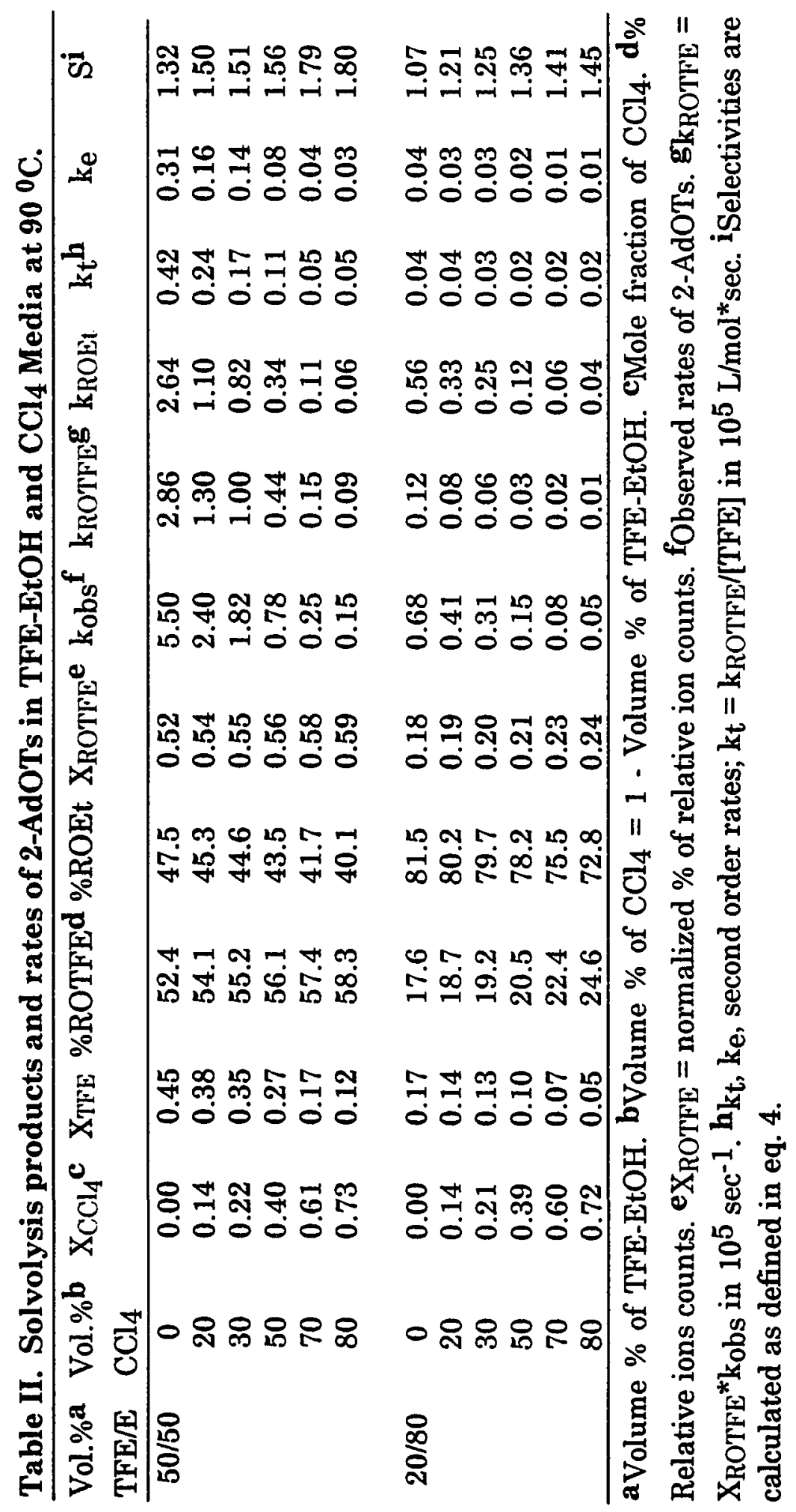









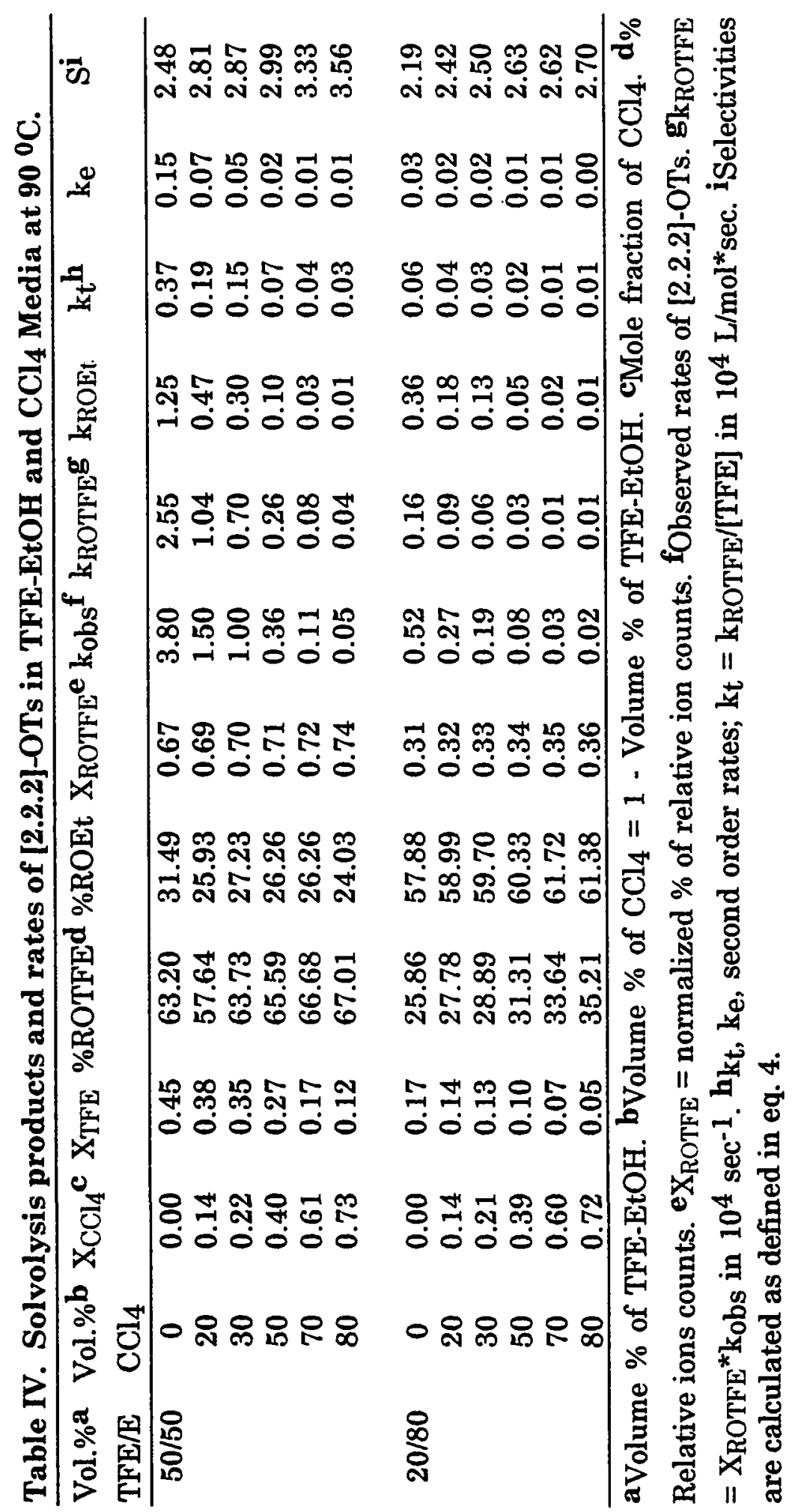




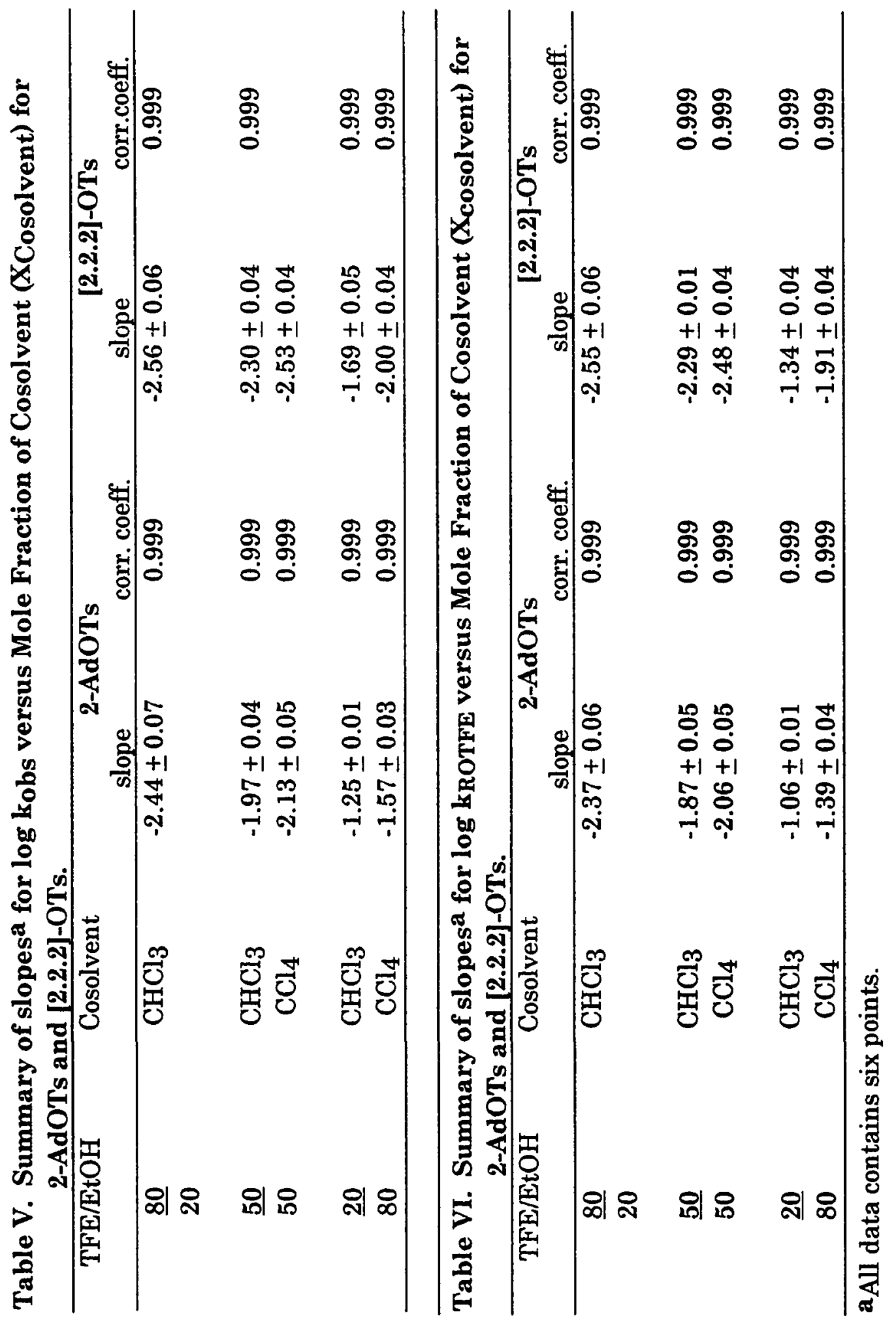









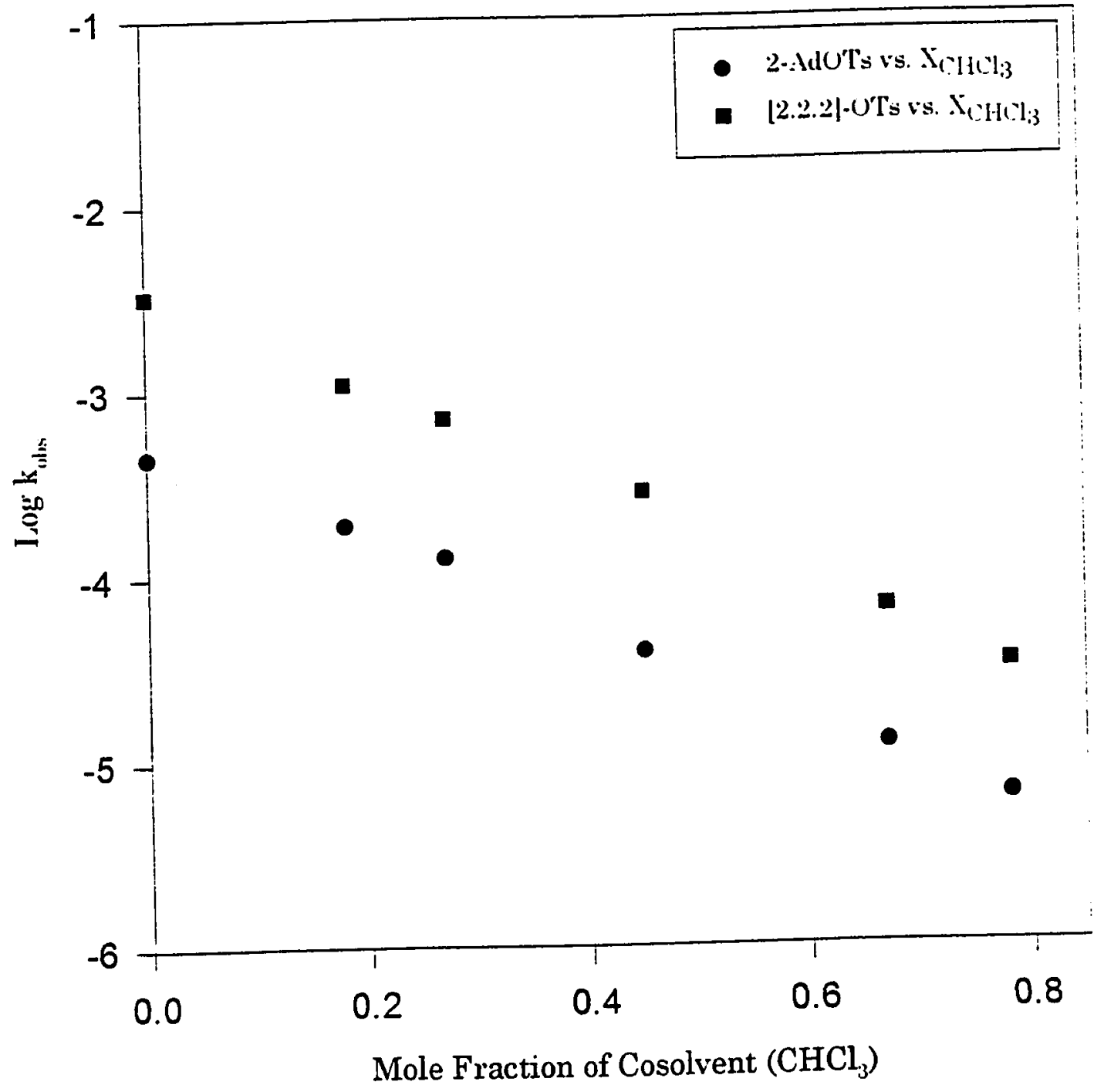

Figure 1. $\log \mathbf{k}_{\text {obs }}$ versus Mole Fraction of Cosolvent $\left(\mathbf{X}_{\mathrm{CHCl}_{3}}\right)$ for 2-AdOTs and [2.2.2]-OTs in 80:20 vol.\% of TFE-EtOH. 


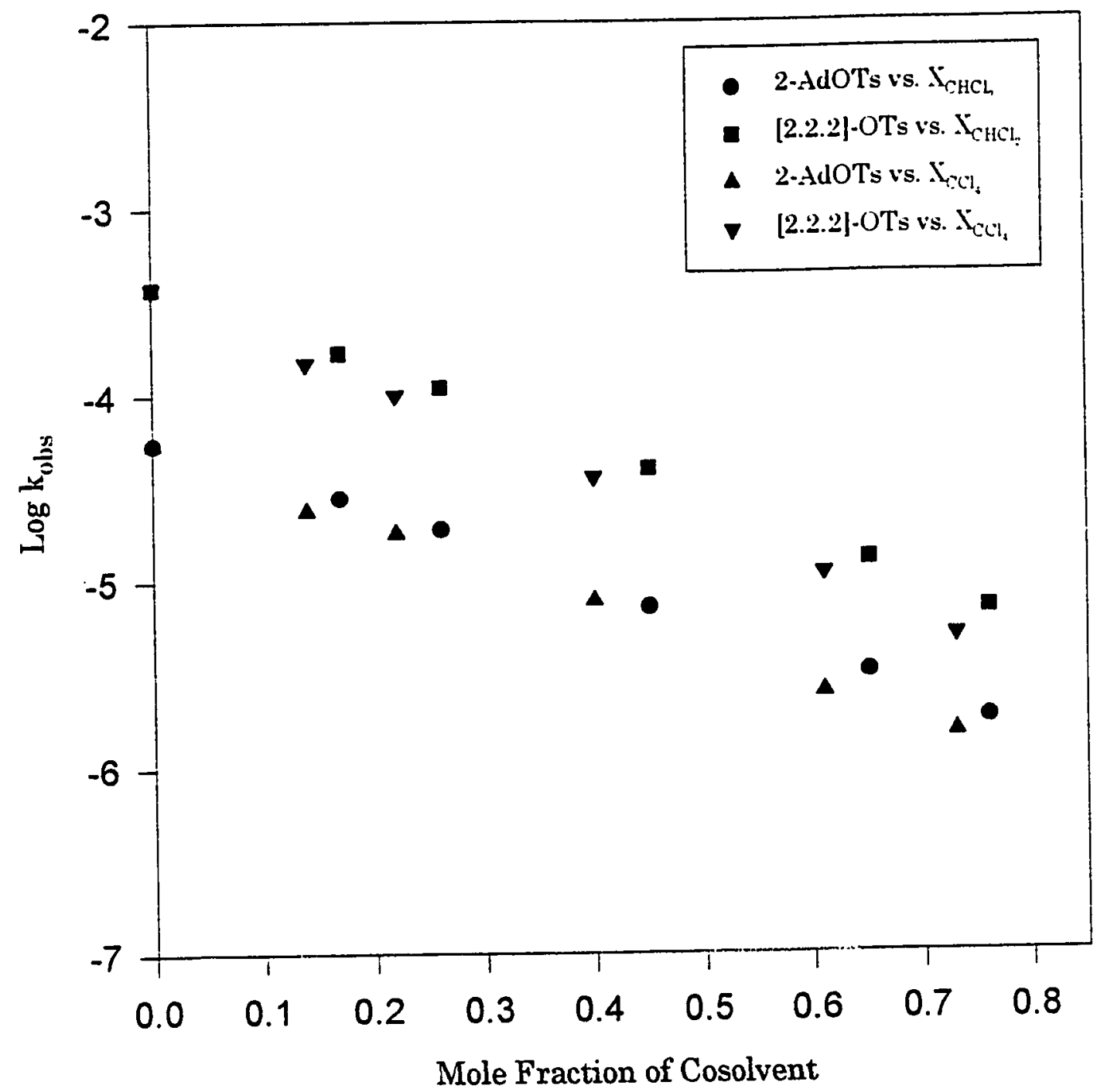

Figure 2. $\log \mathbf{k}_{\text {obs }}$ versus Mole Fraction of Cosolvent $\left(\mathrm{X}_{\mathrm{CHCl}_{3}}\right.$ and $\left.\mathrm{X}_{\mathrm{CCl}_{4}}\right)$ for 2-AdOTs and [2.2.2]-OTs in 50:50 vol.\% of TFE-EtOH. 


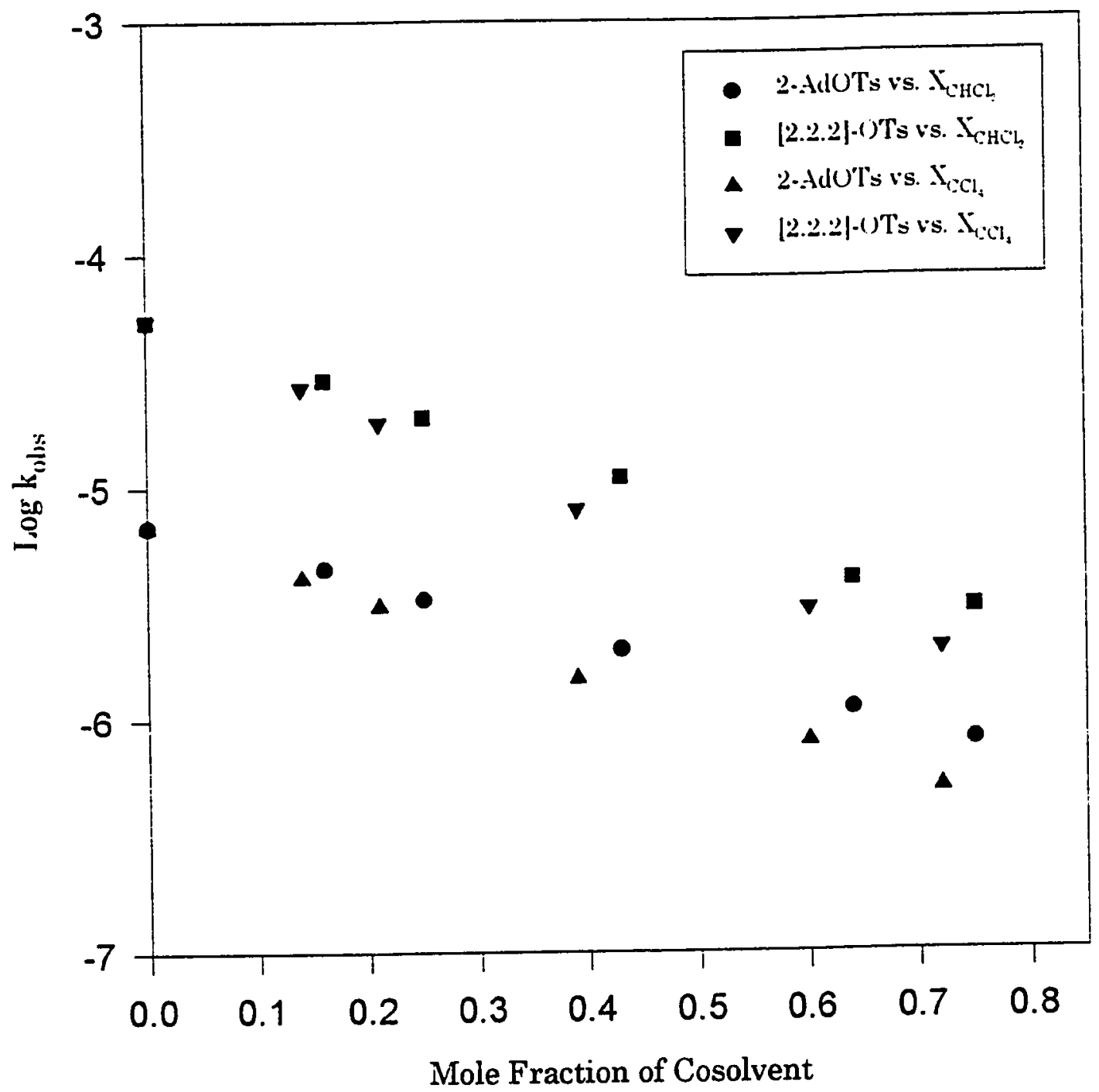

Figure 3. $\log \mathbf{k}_{\text {obs }}$ versus Mole Fraction of Cosolvent $\left(\mathrm{X}_{\mathrm{CHCl}_{3}}\right.$ and $\mathrm{X}_{\mathrm{CCl}_{3}}$ ) for 2-AdOTs and [2.2.2]-OTs in 20:80 vol.\% of TFE-EtOH. 


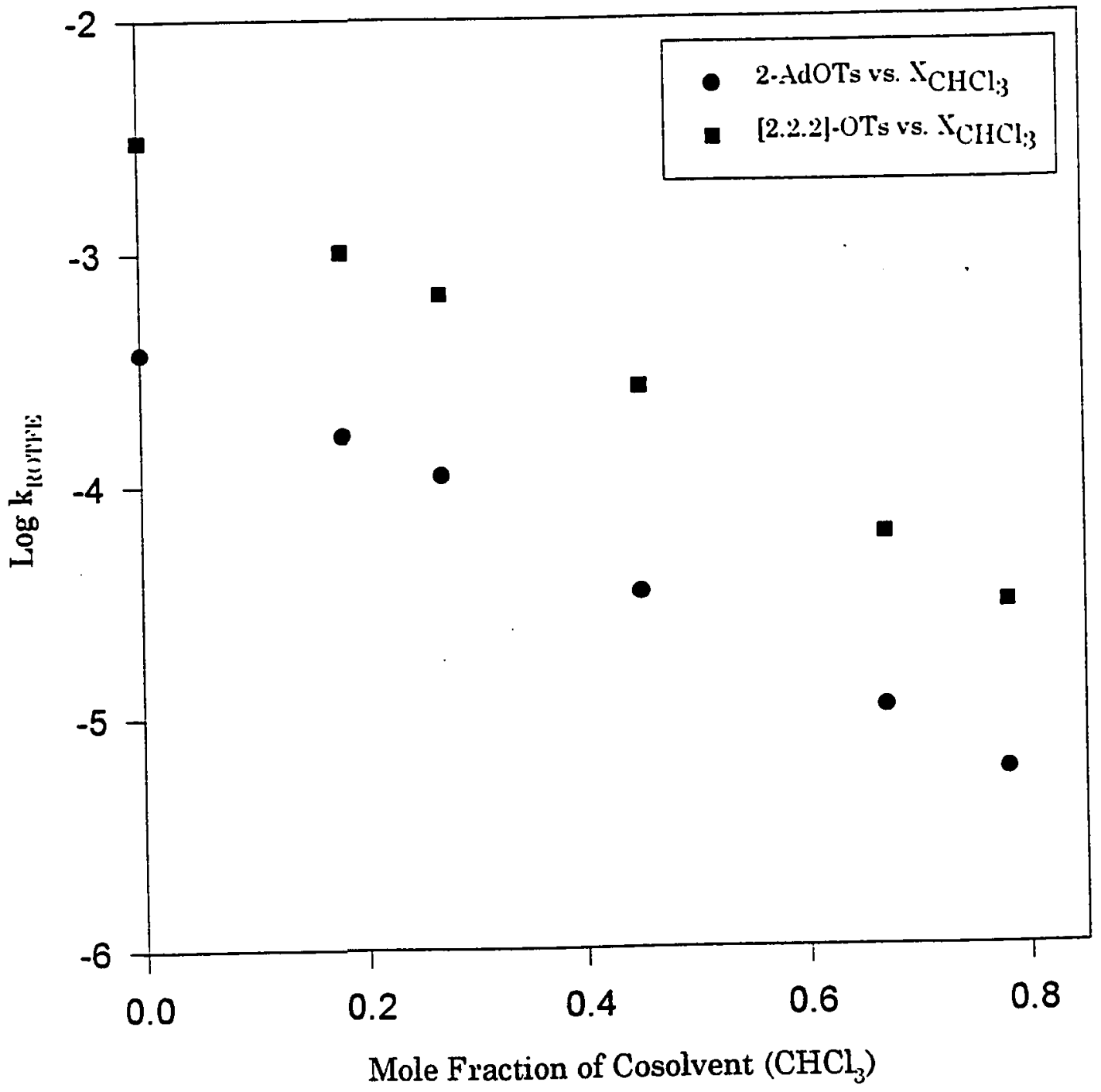

Figure 4. $\log \mathrm{k}_{\mathrm{ROTFE}}$ versus Mole Fraction of Cosolvent $\left(\mathrm{X}_{\mathrm{CHCl}_{3}}\right)$ for 2-AdOTs and [2.2.2]-OTs in 80:20 vol.\% of TFE-EtOH. 


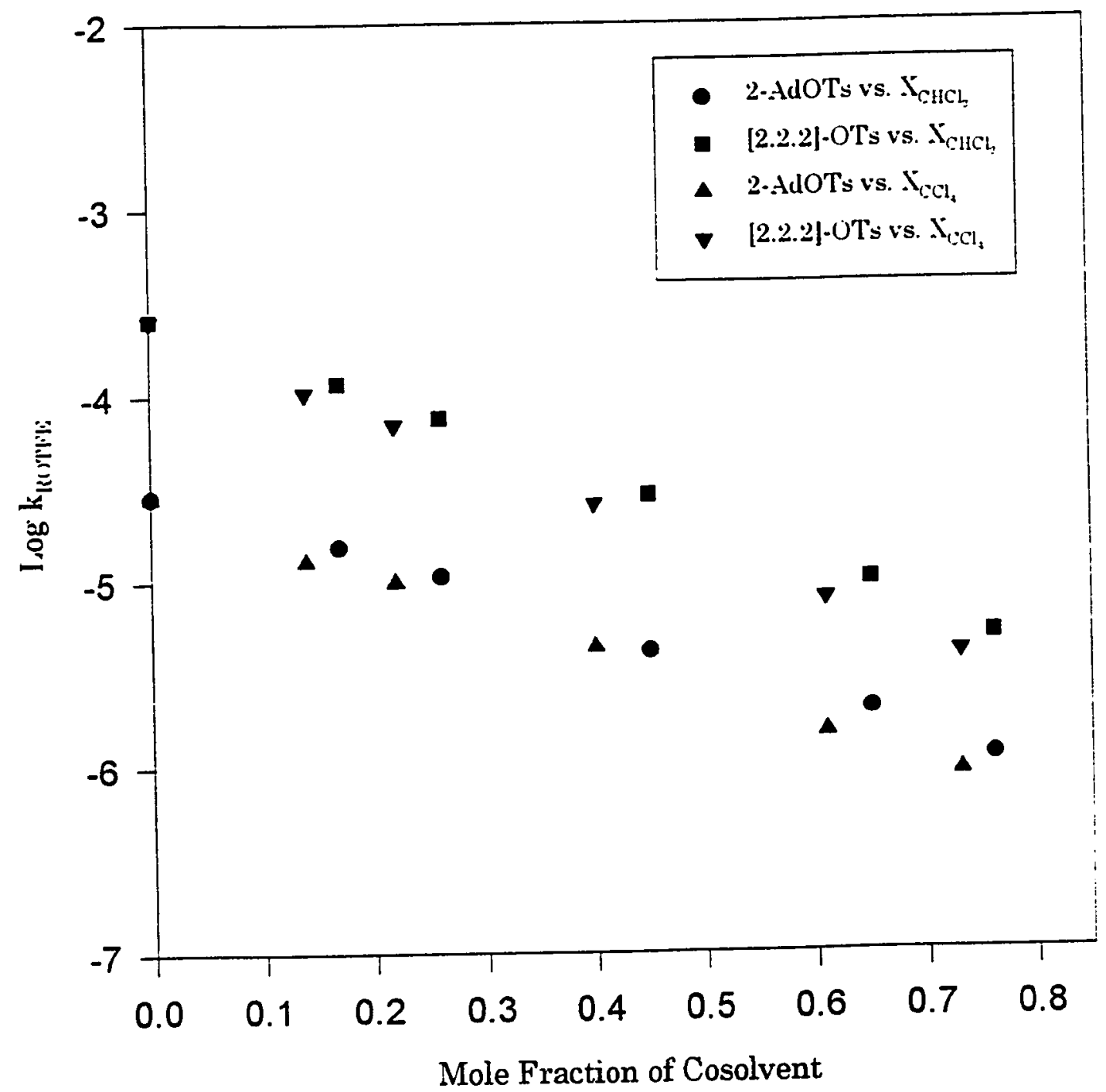

Figure 5. $\log \mathbf{k}_{\mathrm{ROTFE}}$ versus Mole Fraction of Cosolvent $\left(\mathrm{X}_{\mathrm{CHCl}_{3}}\right.$ and $\left.\mathrm{X}_{\mathrm{CCl}_{4}}\right)$ for 2-AdO'Ts and [2.2.2]-OTs in 50:50 vol.\% of TFE-EtOH. 




Figure 6. $\log \mathrm{k}_{\mathrm{ROTFE}}$ versus Mole Fraction of Cosolvent $\left(\mathrm{X}_{\mathrm{CHCl}_{3}}\right.$ and $\mathrm{X}_{\mathrm{CCl}_{4}}$ ) for 2-AdOTs and [2.2.2]-OTs in 20:80 vol.\% of TFE-EtOH. 